\title{
A New Method for Representing Mixed-phase Particle Fall Speeds in Bulk Microphysics Parameterizations
}

\author{
Jimy DUDHIA \\ Mesoscale and Microscale Meteorology Division/National Center for Atmospheric Research, \\ Boulder, Colorado, USA \\ Song-You HONG and Kyo-Sun LIM \\ Department of Atmospheric Sciences, Global Environment Laboratory, Yonsei University, Seoul, Korea
}

(Manuscript received 22 August 2007, in final form 1 March 2008)

\begin{abstract}
Here we present a simple method of improving bulk mixed-phase microphysical schemes to allow for a more realistic representation of partially rimed particles. The new procedure unifies the snow and graupel particles by assigning a single fallspeed to both that is weighted by the mixing ratios, and applying that fallspeed to both sedimentation and accretion processes. This avoids the problem of the species separating out by sedimentation as graupel forms, and the further problem of graupel then accreting snow too quickly because of its high relative fallspeed. Instead the unified graupel/snow moves together and evolves in its relative ratio due to riming, behaving as intermediate or partially rimed particles.

Tests of the new method were carried out using the Weather Research and Forecasting (WRF) SingleMoment 6-class (WSM6) microphysics scheme in a high-resolution idealized simulation, and mesoscale heavy precipitation events in the summer and winter over Korea. The effect of the new accretion rates on cloud structure and precipitation was found to be greater than that of the changed sedimentation alone. Verification of these tests showed a much-reduced production of graupel and more snow, influencing the cloud structure and surface precipitation fields. The scheme shows promise in improving precipitation intensity and precipitation type forecasts.
\end{abstract}

\section{Introduction}

Bulk microphysical parameterizations that represent mixed-phase processes divide particles into categories such as snow and graupel or hail. The distinction between these is in the primary habit of the particles, where snow is assumed to be unrimed ice crystals or aggregates of crystals that have predominantly grown by deposition of ice, while graupel and hail have grown mostly by collection of water droplets, and are therefore denser

Corresponding author: Song-You Hong, Department of Atmospheric Sciences, Yonsei University, Seoul 120-749, Korea.

E-mail: shong@yonsei.ac.kr

(C)2008, Meteorological Society of Japan and rounder than the snow category. This distinction is important in numerical models because the density of the particles affects process rates, and particularly the fall speed of the particles that in turn affects cloud structure and precipitation intensity.

Some mesoscale microphysical parameterizations (e.g., Dudhia 1989; Hong et al. 2004), designed for grid sizes greater than about $10 \mathrm{~km}$, have no category for rimed particles because when convection is unresolved, the primary riming process is also unlikely to be resolved because watersaturated updrafts are not explicitly represented. Parameterized convective clouds in such mesoscale models create the precipitation due to unresolved updrafts, and processes such as graupel 
production are implicit in their sub-grid treatment. If these "mesoscale" microphysics schemes are applied at cloud-resolving scales, with no cumulus parameterization scheme, the lack of a graupel category shows up as a marked deficiency in surface precipitation intensity due to the slow fall speed of snow compared to that of graupel. Addition of a rimed category, such as hail or graupel alleviates this problem, and the widely used bulk cloud microphysical schemes for cloud-resolving simulations generally have such a category (e.g., Lin et al. 1983; Reisner et al. 1998; Hong and Lim 2006; Thompson et al. 2004, 2006).

In reality, of course, there is no such clear distinction between snow and graupel in clouds, and there are many degrees of riming between these extremes. By labeling particles as either snow or graupel, bulk schemes are unable to represent this continuum of habits, and, due to the assumptions about these habits there is a partitioning in behavior that is not likely to be so well defined in nature. Probably the most extreme difference would be due to the factor or two or three in the assumed fall speeds for a given mass content as graupel has a much greater density (further enhanced for hail). This difference in turn leads to a separation of trajectories of snow and graupel within the same modeled cloud, even when they have the same origin.

In typical bulk schemes, graupel originates from snow that rimes by contact with cloud water or rain, and in general the mass content of snow will reduce while the graupel mass content increases as riming proceeds. When both graupel and snow are present, graupel mass is further enhanced by accretion of snow due to its relative fall speed. Other accretion and deposition processes also lead to changes in snow and graupel mass contents.

In this paper, we introduce a simple method to alleviate the problem of species separation by revising the paradigm that a particle is either graupel or snow, particularly in the treatment of its fall speed, and hence trajectory, thus preventing a false separation and enhanced accretion due to their relative sedimentation rates.

\section{Modifications to the WSM6 scheme}

The Advanced Research WRF (ARW; Skamarock et al. 2005) is a community model suitable for both research and forecasting. This model is well suited for idealized types of simulations to study baroclinic waves, idealized storm dynamics, or topographi- cally induced flows as well as for detailed NWP cases with real-data initial states and boundary conditions. The model used in this study is WRF ARW version 2.1.2, which was released in January 2006.

The WRF-Single-Moment-Microphysics (WSMMPs) include the WSM3, WSM5 and WSM6 schemes having a revised ice process treatment of Hong et al. (2004). The names WSM3, WSM5 and WSM6 denote the number of categories of water species, including vapor, predicted by the scheme. The most distinguishing features of the WSMMPs are that they practically represent ice microphysical processes by (1) assuming the ice nuclei number concentration to be a function of temperature, and (2) they include the new separate assumption that the ice crystal number concentrations are a function of the amount of ice. In the WSM6 scheme, the 6-class prognostic water substance includes the mixing ratios of water vapor $\left(q_{v}\right)$, cloud water $\left(q_{c}\right)$, cloud ice $\left(q_{i}\right)$, snow $\left(q_{s}\right)$, rain $\left(q_{r}\right)$, and graupel $\left(q_{g}\right)$. A more detailed description of the WSM6 scheme including the production terms and the computational procedure is given in Hong and Lim (2006). Another update is included in these experiments. Accretion of cloud water by snow is now treated as a source term for snow, not for graupel, if $\mathrm{T} \leq \mathrm{T} 0$. This is in the current WSM6 option in WRF (i.e., in version 2.2).

The underlying new assumption introduced in this paper is that graupel and snow that inhabit the same grid box have the fall properties of an intermediate (partially rimed) particle that is weighted by the snow and graupel contents of the grid box. The basis of this assumption is that riming does not affect snow particles in a grid box, turning just those into graupel and leaving other snow particles unaffected. Instead riming affects all snow particles equally, and it is therefore unrealistic to treat any affected particles as pure snow (likewise pure graupel), but more realistic to treat all particles equally, and as rimed to the same degree, at least in terms of the mass-weighted fall speed applied. For example, a grid box may contain $90 \%$ of its total hydrometeor mass as snow and $10 \%$ as graupel. Rather than treating these independently as pure snow and pure graupel particles with separate fall speeds, we treat all the particles as hybrid lightly-rimed particles with a single weighted fall speed, which we regard as more realistic given the common histories of these particles.

Given this assumption, the mass-weighted veloc- 
ity for both species can be expressed as

$$
\bar{V}_{g s}\left[\mathrm{~m} \mathrm{~s}^{-1}\right]=\frac{q_{s} \bar{V}_{s}+q_{g} \bar{V}_{g}}{q_{s}+q_{g}},
$$

where the subscripts $s$ and $g$ denote snow and graupel. The resulting relation of the new velocity with graupel and snow mixing ratios is plotted in Fig. 1. As expected, the combined sedimentation velocity is more sensitive to the amount of graupel, than that of snow, which is due to the larger density for graupel than for snow. The magnitude of the velocity increases as the amount of graupel (snow) increases (decreases); however, it is noted that there is a range for the increase of it, with respect to the amount of snow, when the amount of graupel is relatively small.

Assigning all particles the same mass-weighted fall speed has the added consequence that the process of accretion of snow by graupel is also eliminated, because accretion only occurs due to large relative fall speeds. The modified scheme proposed here therefore has two major components, (i) a new mass-weighted fall speed, and (ii) modified accretion rates including elimination of snow-graupel accretion. We will separately test accretion process changes and the new combined

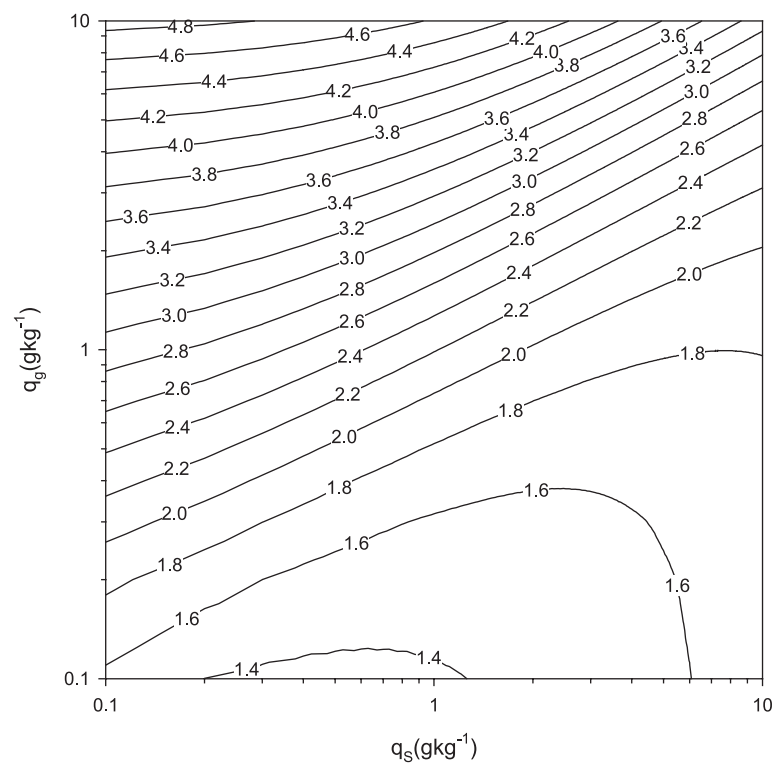

Fig. 1. Mass weighted terminal velocity $\left(\mathrm{m} \mathrm{s}^{-1}\right)$ as a function of graupel and snow amount with the assumption that the air temperature is $-10^{\circ} \mathrm{C}$. weighted fall speed to show the individual effects of these two new features of the scheme. All other snow and graupel processes, such as deposition, sublimation, and melting, are left as before, acting on the individual snow and graupel contents, which is also equivalent to linearly mass-weighting these processes with the snow-graupel ratio. Accretion processes with ice, cloud water and rain use the new fall speed.

The benefit of such a scheme is that as riming begins, the snow/graupel weight is more towards snow, and the fall speed is more like snow, but as riming completes, the mixture transitions towards a graupel fall speed. This is perceived as giving a more realistic evolution of the bulk properties of the cloud than the bimodal fall speed distribution and consequent gravitational species separation inherent in current bulk schemes. Note that the scheme is still technically a 6-class scheme because six moisture species arrays are necessary. However, when viewing output from such a scheme, it is the snow-plus-graupel total and the graupel/snow ratio that should be regarded as independent fields, rather than snow and graupel fields individually.

\section{Numerical experimental setup}

Two sets of experiments were carried out using an idealized 2D thunderstorm case, a 3D real-data simulation for a heavy rainfall event, and a heavy snowfall event over Korea. As mentioned, these experiments additionally separate the effects of the modifications on the sedimentation and on the accretion processes to determine their relative importance.

\section{a. Idealized thunderstorm experiment}

The idealized thunderstorm simulation is a preset option for the WRF model. We chose a 2D domain in the $\mathrm{x}$ direction. The grid in this direction comprised 201 points with a $250-\mathrm{m}$ grid spacing. The number of vertical layers was 80 . The model was integrated for $60 \mathrm{~min}$ with a time step of $3 \mathrm{~s}$. The initial condition included a warm bubble with a $4-\mathrm{km}$ radius and a maximum perturbation of $3 \mathrm{~K}$ at the center of the domain. A wind with a velocity of $12 \mathrm{~m} \mathrm{~s}^{-1}$ was applied in the positive $\mathrm{x}$ direction at the surface; its velocity decreased to zero at 2.5 $\mathrm{km}$ above the ground, with no wind above. Open boundary conditions were applied, and there was no Coriolis force or friction. The only physical parameterization was the microphysics scheme, 
Table 1. A summary of sensitivity experiments to the new terminal velocity for snow and graupel.

\begin{tabular}{ll}
\hline Code & \multicolumn{1}{c}{ Description } \\
\hline Exp1 & $\begin{array}{l}\text { WSM6 microphysics (current option in ver- } \\
\text { sion 2.2) }\end{array}$ \\
Exp2 & $\begin{array}{l}\text { Replacing the sedimentation velocities for } \\
\text { snow and graupel to new ones }\end{array}$ \\
Exp3 & $\begin{array}{l}\text { Replacing the accretion terms by using the } \\
\text { new velocities for snow and graupel } \\
\text { Exp4 }\end{array}$ \\
accretions (Exp2 + Exp3) \\
\hline
\end{tabular}

and other physical processes were turned off.

Four experiments are designed as summarized in Table 1. Exp1 is the current WSM6 scheme in WRF. Exp2 replaces the sedimentation velocities of snow and graupel with the new ones from Eq. (1), Exp3 alters only accretion terms with the new velocities. The accretion of snow by graupel (Pgacs) is also taken out in Exp3. Exp4 considers both effects from Exp2 and Exp3.

\section{b. Heavy rainfall (snowfall) event}

A significant amount of precipitation was recorded in Korea on July 15, 2001, with a local maximum of approximately $371.5 \mathrm{~mm}$ near Seoul (Fig. 2a). The central districts of the Korean peninsula received a significant amount of precipitation, with a local maximum of about $69.8 \mathrm{~mm}$ on March 4-5, 2004 (Fig. 2b). A more detailed synoptic overview for heavy rainfall and snowfall cases is available in Hong and Lim (2006) and Jung et al. (2005), respectively. The physics packages other than the microphysics include the Kain-Fritsch (1993) cumulus parameterization scheme, the Noah landsurface model (Chen and Dudhia 2001), the Yonsei University planetary boundary layer (PBL) (Hong et al. 2006), a simple cloud-interactive shortwave radiation scheme (Dudhia 1989), and Rapid Radiative Transfer Model (RRTM) longwave radiation (Mlawer et al. 1997) scheme.

The model configuration consisted of a nested domain configuration using the Lambert conformal projection (Fig. 3). A 5-km model covering the Korean peninsula (Domain 3, $181 \times 181$ ), was surrounded by a $15-\mathrm{km}$ grid model (Domain $2,100 \times$ 100 ), which in turn was surrounded by a $45-\mathrm{km}$ grid model (Domain $1,80 \times 80$ ) by a one-way interaction. No cumulus parameterization was used at the 5 -km grid model.

Four experiments, Exp 1-4, as in the idealized run are conducted. The experiments for a heavy rainfall were carried out for $24 \mathrm{~h}$, from 0000 UTC July 14 to 0000 UTC July 15,2001 . The experimental setup for snowfall is the same as that in the summer case introduced above, except for the simulation time of $36 \mathrm{~h}$ starting at 00 UTC March 4, 2005.

(b)

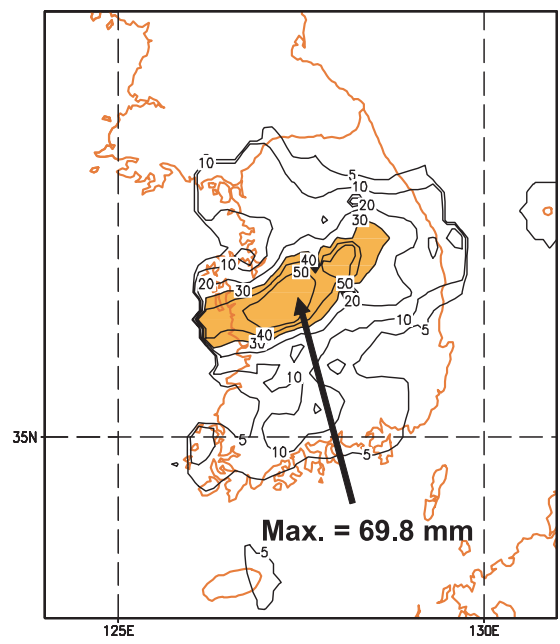

Fig. 2. Observed (a) 24-h accumulated precipitation (mm) valid at 0000 UTC 15 July 2001 for the summer case, (b) 36-h accumulated precipitation (mm) valid at 1200 UTC 05 March 2004 for the winter case. 


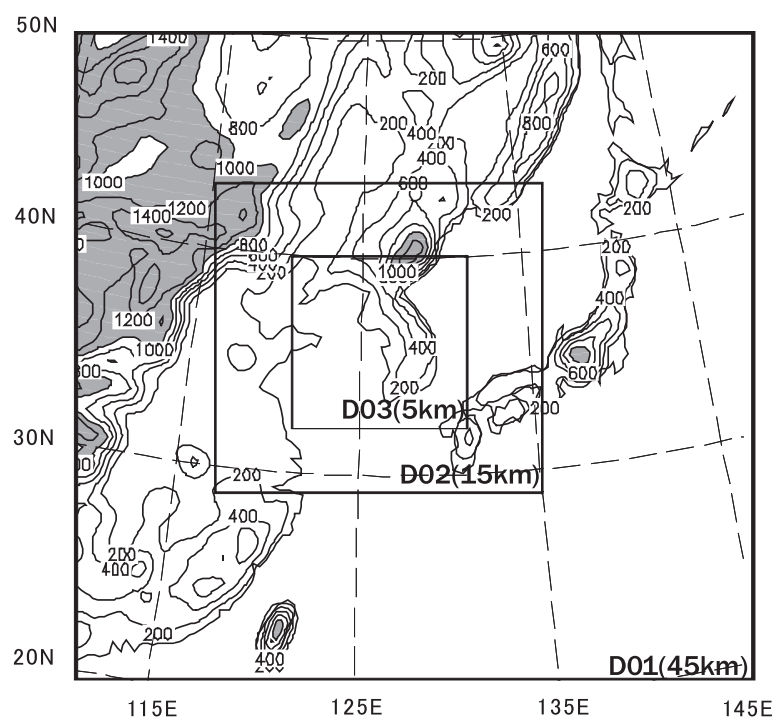

(a)
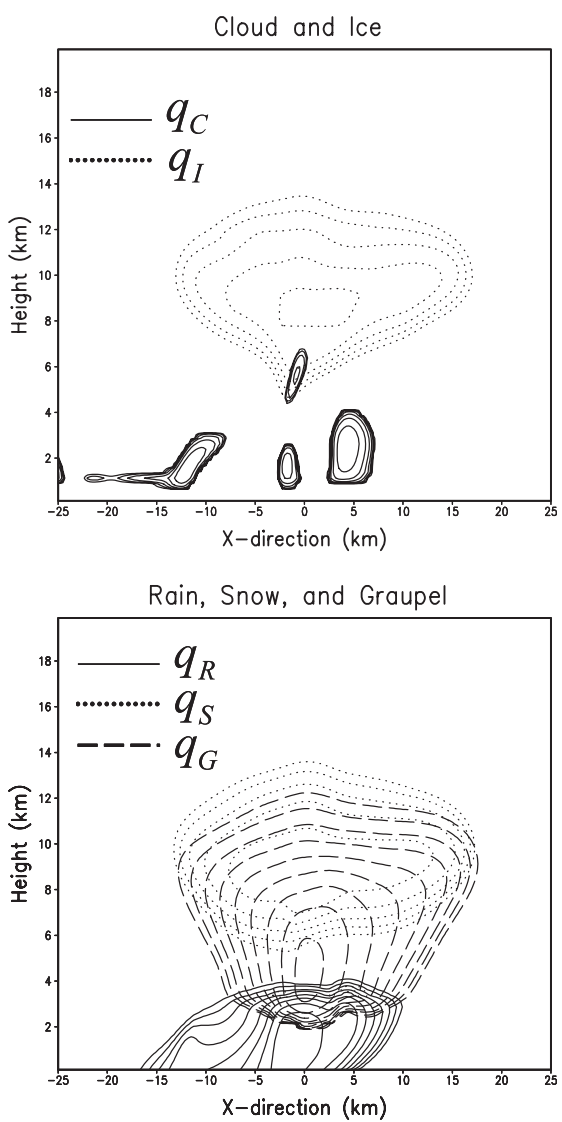

\section{Results and discussion}

a. Idealized experiments

Figure 4 compares the condensate fields from Exp4 to those from Exp1. It is noted that the revised scheme considers snow and graupel as hybrid, but the sum of snow and graupel gives less information than the model has, because the ratio of snow to graupel is also an important factor in how the particles are treated. Thus, shown in Fig. $4 \mathrm{~b}$ are the separate contours for snow and graupel.

Fig. 3. Model terrain contoured every $100 \mathrm{~m}$ for $45-\mathrm{km}$ (D01). The resolutions of inner domains (D02 and D03) are $15-\mathrm{km}$ and 5-km. Terrain heights greater than $1000 \mathrm{~m}$ are shaded.

(b)
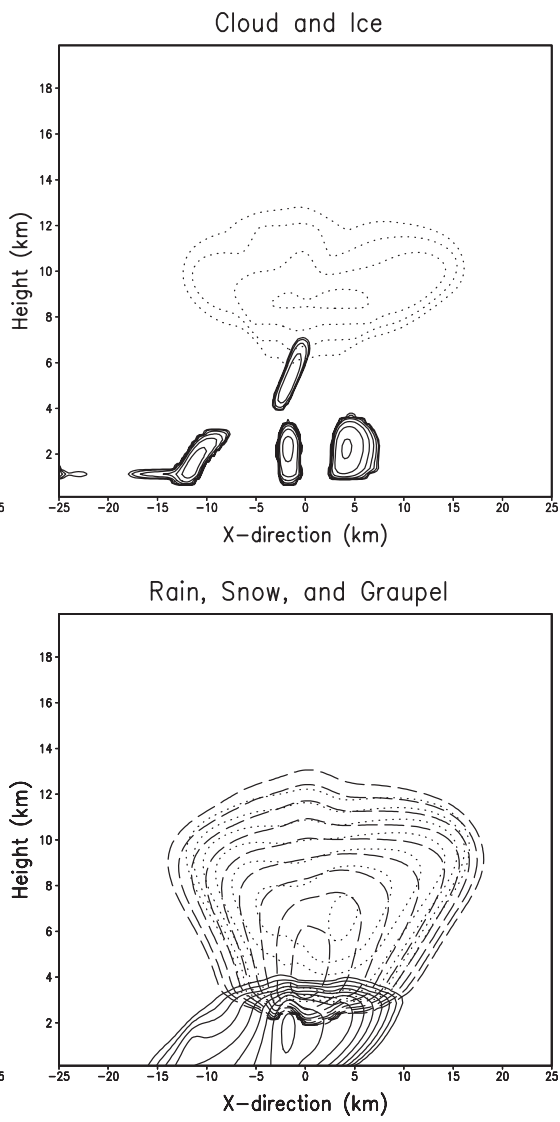

Fig. 4. Isolines of the condensation fields for cloud particles (first low), cloud ice $\left(q_{i}\right.$; shaded), cloud water $\left(q_{c}\right.$; solid), and for precipitable particles (second row), rain $\left(q_{r}\right.$; shaded), snow $\left(q_{s}\right.$; short dashed) and graupel ( $q_{g}$; long dashed), from (a) Exp1, and (b) Exp4 experiments. Contour lines are at $0.01,0.02,0.04,0.08,0.16,1.28,2.56,5.12$, and $10.24 \mathrm{gkg}^{-1}$. 
As seen in Hong and Lim (2006), the current option of the WSM6 shows its capability of simulating of fundamental features of a well organized thunderstorm. The general structure of the thunderstorm, such as the cloud droplets and ice particles near the storm center, is well simulated. Cloud condensate reaches a maximum in the middle troposphere in the area of the updraft for both experiments. Apparently, these basic features of the simulated storm are unchanged from Exp1 to Exp4, but it is seen that in Exp4 the amount of cloud ice is reduced, as compared to that in Exp1. A closer inspection shows that the amount of snow is reduced in the anvil clouds, whereas an increase of snow is seen at warmer temperatures as the

(a)

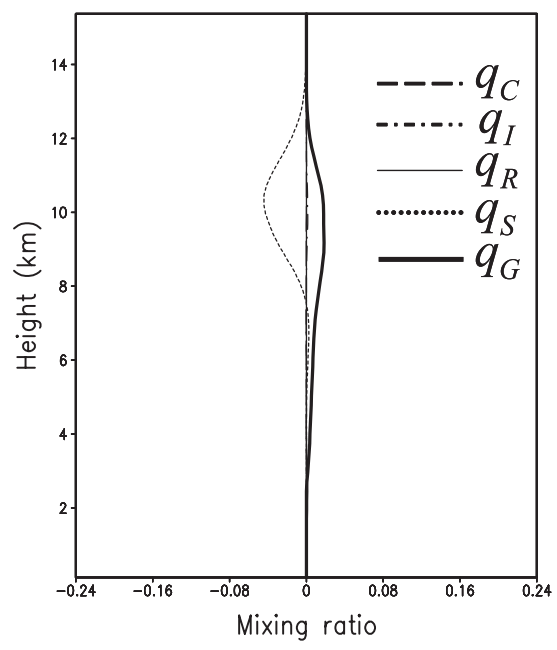

(b)

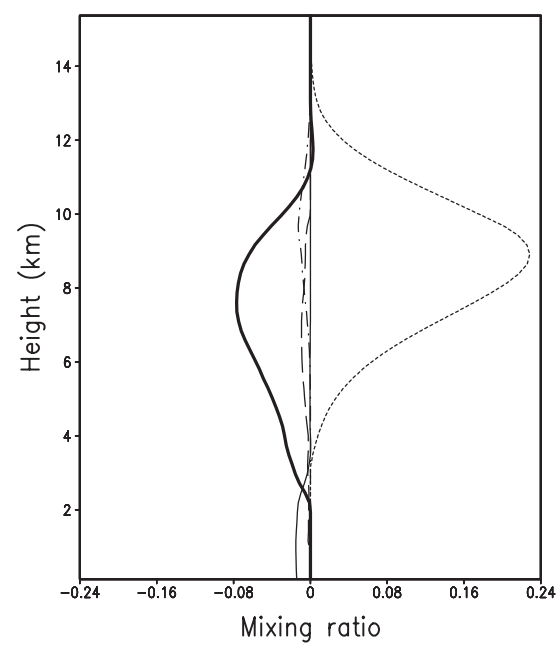

new sedimentation velocity is introduced. As mentioned earlier, there are two kinds of modifications in the new sedimentation formula: 1) sedimentation velocity, and 2) accretion rate. The individual effects of these changes on the simulated storm will be better seen below.

The vertical profiles of differences of Exp2, Exp3 and Exp4, from Exp1, in the time-domain-averaged condensates are plotted in Fig. 5. It is seen that replacing the sedimentation velocity for snow and graupel decreases (increases) the amount of snow (graupel) in the middle-upper atmosphere from $6 \mathrm{~km}$ to $13 \mathrm{~km}$, where both species coexist (Fig. $5 \mathrm{a})$. The reduction (increase) of snow (graupel) is due to the enhanced (reduced) sedimentation

(c)

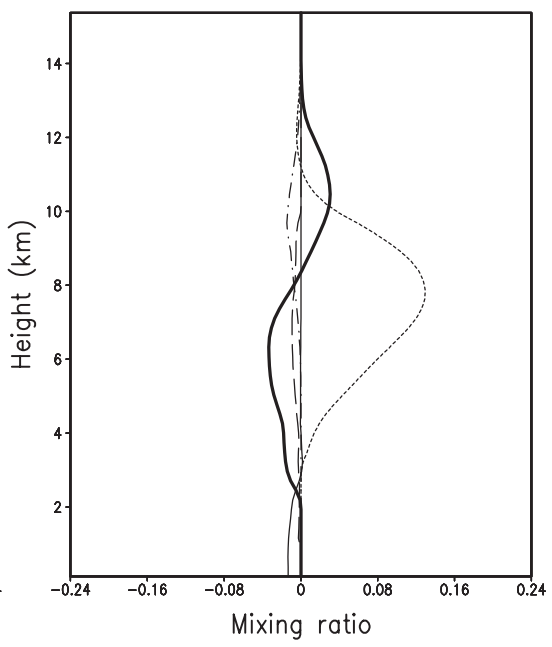

Fig. 5. Vertical distribution of the differences in the domain-averaged water species from Exp1 during the $60 \mathrm{~min}$ integration period, (a) Exp2 minus Exp1, (b) Exp3 minus Exp1, and (c) Exp4 minus Exp1 experiments. Units are $\mathrm{gkg}^{-1}$ for rain, snow, and graupel, and $10 \mathrm{gkg}^{-1}$ for cloud ice and cloud water. 
rate due to the newly combined terminal velocity for snow and graupel, as compared to the profiles with the conventional fall speeds. A more distinct impact is found by the changes in the accretion terms due to the new combined velocity (Fig. $5 \mathrm{~b}$ ). The increase of snow and decrease of graupel are pronounced. Among the changed microphysics terms, the removal of snow-graupel accretion (pgacs) was found to be a major factor in accounting for the changes in hydrometeors. Other hydrometeors such as cloud water, ice, and rain are slightly reduced, which means that the decreased accretion of these particles due to the reduced velocity for graupel dominates over the enhanced snow-accretion due to enhanced terminal velocity for snow. Reduction of graupel at the melting level brings about a reduced rainfall conversion from graupel, which leads to the decrease of surface rainfall during this phase of the convective system. Both sedimentation and accretion processes due to a new combined terminal velocity tend to offset, but the latter effect is more pronounced (Fig. 5c). However, at upper levels the reduction in sedimentation of graupel allows its mixing ratio to exceed that of snow near cloud top as also seen in Fig. 4b. From the time series of domain-averaged precipitation rate and hydrometeor path (not shown), it was found that a weaker precipitation intensity exists in (a)

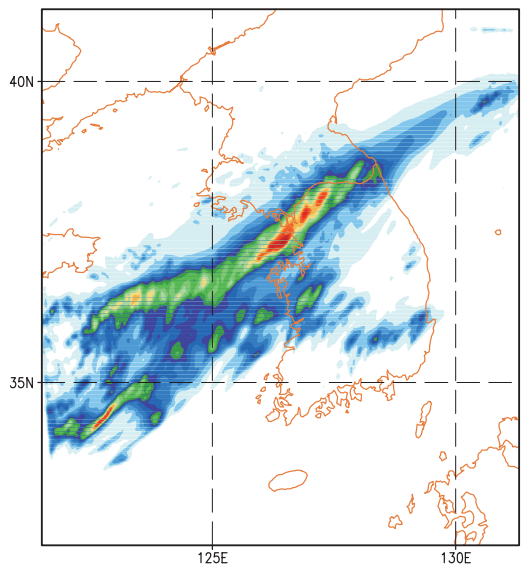

(b)

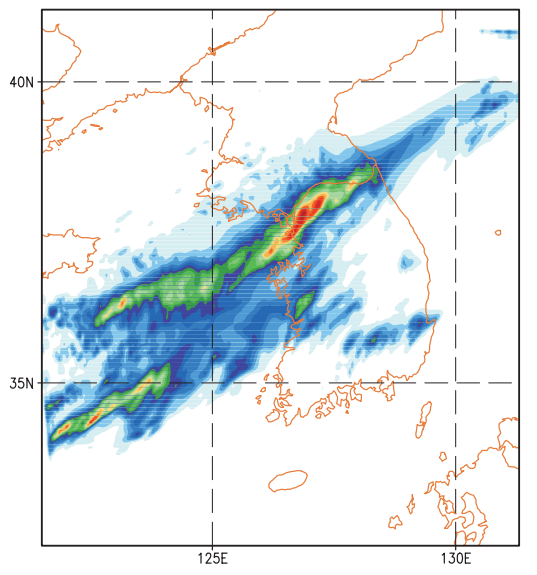

(c)

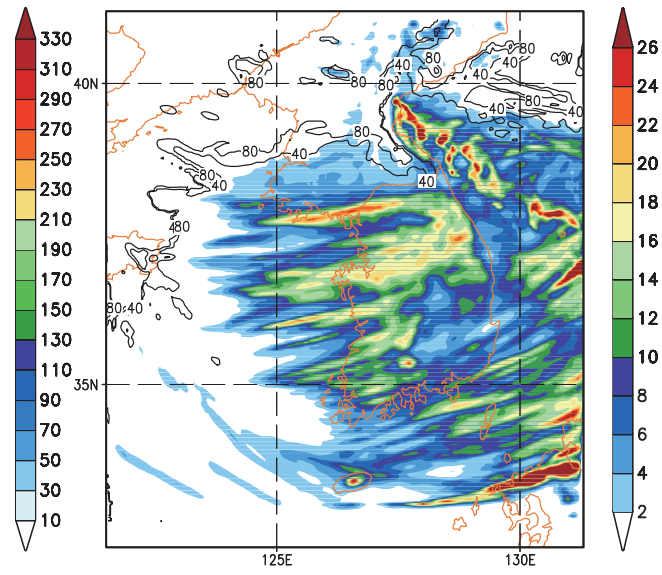

(d)

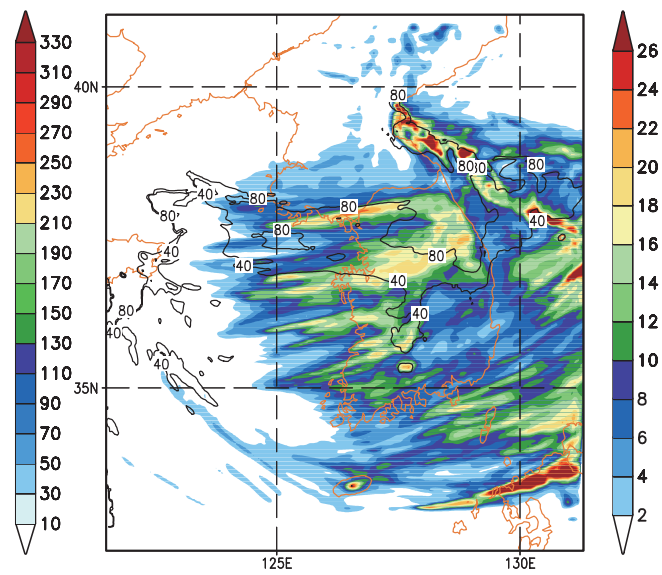

Fig. 6. 24-hr accumulated precipitation (mm) ending at 0000 UTC 15 July 2001, from (a) Exp1, and (b) Exp4, and 36-hr accumulated precipitation (mm) ending at 1200 UTC 05 March 2004, from (c) Exp1, and (d) Exp4 experiments. Contour lines in (c) and (d) indicate the percentage of precipitation due to snow. Results are obtained with the 5 -km grid interval experiments. 
Exp3 and Exp4, which is due to the reduced graupel melting process that converts graupel into rain water when the temperature is above $0^{\circ} \mathrm{C}$. More remaining hydrometeors in the atmosphere in Exp3 and 4 were consistent with less precipitation than in Exp1 and 2, and with the overall reduction in fall speed in the new scheme.

\section{b. Heavy rainfall (snowfall) event}

Figure 6 shows the results of the simulated precipitation obtained from the heavy rainfall and snowfall experiments. We can see that the results from the Exp1 and Exp4 do not show significant differences in the distribution of precipitation. In the summer case, observed heavy rainfall extending from southwest to northeast across the central part of the Korean peninsula is well captured in both simulations (compare Figs. 6a, b, and Fig. 2a). The statistics of simulated precipitation over South Korea (Table 2) reveal a slight improvement of the pattern correlation by reducing the amount of precipitation in the $45-\mathrm{km}$ run, but the skill for the $5-\mathrm{km}$ experiments do not show a systematic difference. The maximum amount of precipitation is decreased in Exp3, whereas it is increased in Exp2. In terms of domain-averaged precipitation, the new terminal velocity plays a role in reducing the total amount of precipitation.
For the wintertime snowfall case, the distribution of snowfall covering the Korean Peninsula is well reproduced by both experiments (compare Figs. $6 \mathrm{c}, \mathrm{d}$ and $2 \mathrm{~b}$ ). The pattern correlation coefficients are similar for Exp 1-4 (Table 3). The resulting impacts of the changes in sedimentation and accretion processes on the simulated precipitation comply with the behaviors analyzed in the 2D thunderstorm case. For example, the changes in sedimentation do not affect the resulting precipitation, but the amount of precipitation is decreased by the modified accretion processes with the new terminal velocity, which is closer to what was observed. One of the reasons for a more robust impact for the winter case run can be attributed to the fact that winter snowfall is significantly affected by the ice microphysics under the synoptically strong environment, whereas in the heavy rainfall case the importance of ice-microphysics is relatively small.

Figure 7 compares the vertical profiles of averaged condensates over the heavy precipitation region centered in Korea. The results from Exp1 and Exp4 produce similar profiles for ice, clouds, and rain, but not for snow and graupel, as was also seen in the idealized experiments. In both cases, increased snow and reduced graupel are the dominant differences through the entire atmosphere in Exp4. For summer case (Figs. 7a, b), graupel pen-

Table 2. The pattern correlation coefficients (PC) and bias score of the 24-hr accumulated precipitation over South Korea with respect to surface observation, ending at 00 UTC 15 July 2001, for 5-km(45 km) resolution.

\begin{tabular}{cccccc}
\hline & \multicolumn{3}{c}{ Over South Korea } & & Over whole domain \\
\cline { 2 - 3 } \cline { 5 - 5 } & Correlation & Bias score & Maximum $(\mathrm{mm})$ & & Average (mm) \\
\hline Exp1 & $0.66(0.69)$ & $1.66(1.70)$ & $321(200)$ & & $23.21(21.04)$ \\
Exp2 & $0.64(0.74)$ & $1.64(1.55)$ & $361(208)$ & & $22.93(19.22)$ \\
Exp3 & $0.67(0.76)$ & $1.67(1.51)$ & $299(202)$ & & $22.52(18.72)$ \\
Exp4 & $0.65(0.75)$ & $1.65(1.54)$ & $325(214)$ & & $22.83(19.01)$ \\
\hline
\end{tabular}

Table 3. Same as in Table 2 but for the heavy snowfall simulation, ending at 12 UTC 05 March 2004, for 5-km (45 km) resolution.

\begin{tabular}{cccccc}
\hline & \multicolumn{3}{c}{ Over South Korea } & & Over whole domain \\
\cline { 2 - 3 } \cline { 5 - 5 } & Correlation & Bias score & Maximum $(\mathrm{mm})$ & & Average $(\mathrm{mm})$ \\
\hline Exp1 & $0.52(0.62)$ & $1.75(1.70)$ & $29(19)$ & \\
Exp2 & $0.53(0.62)$ & $1.74(1.70)$ & $25(19)$ & & $6.74(6.45)$ \\
Exp3 & $0.51(0.61)$ & $1.66(1.67)$ & $22(20)$ & & $6.42(6.36)$ \\
Exp4 & $0.51(0.61)$ & $1.69(1.67)$ & $24(20)$ & & $6.52(6.33)$ \\
\hline
\end{tabular}


etrating above the snow that was seen in the 2D run does not appear in Exp4 (cf., Fig. 4b). The new scheme induces a more realistic surface precipitation type, with more snow than graupel contributing to the surface precipitation (cf., Figs. 7c and $7 d$ ) in the snowfall case.

Scatter plots of mixing ratios of graupel and snow over the heavy precipitation region are shown in Fig. 8. These show that the graupel and snow change from uncorrelated fields to correlated ones because of their unified fall speeds, and that in both these cases, all snow is affected to some degree by riming, because no significant amounts of pure snow remain. In the summer case, the typical ratio of snow to graupel from Fig. $8 \mathrm{~b}$ is around $1: 1$, while in the winter case (Fig. 8d) it increases to $3: 1$, which is a measure of the relative degrees of riming between these cases. The original scheme, on the other hand, had higher average ratios of graupel to snow in both cases, but no well-defined ratio.

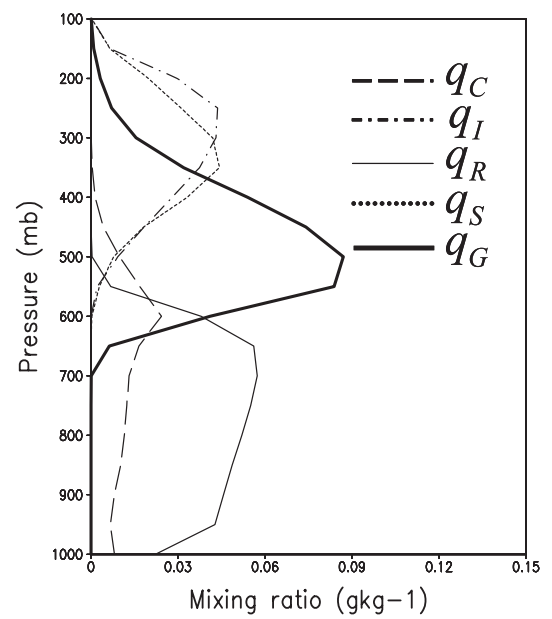

(b)

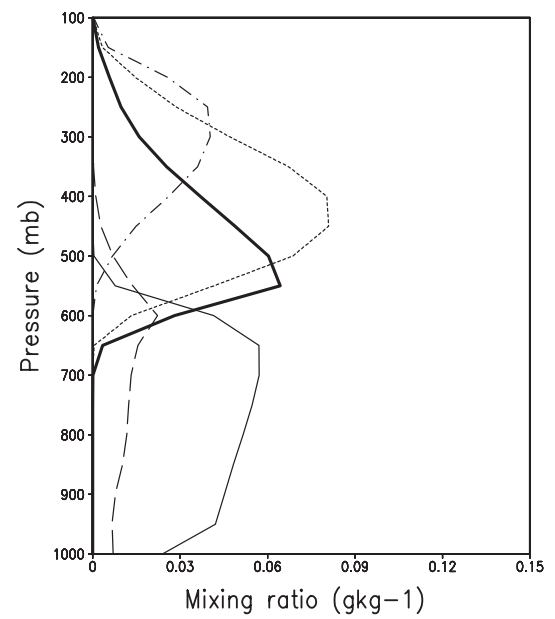

(c)

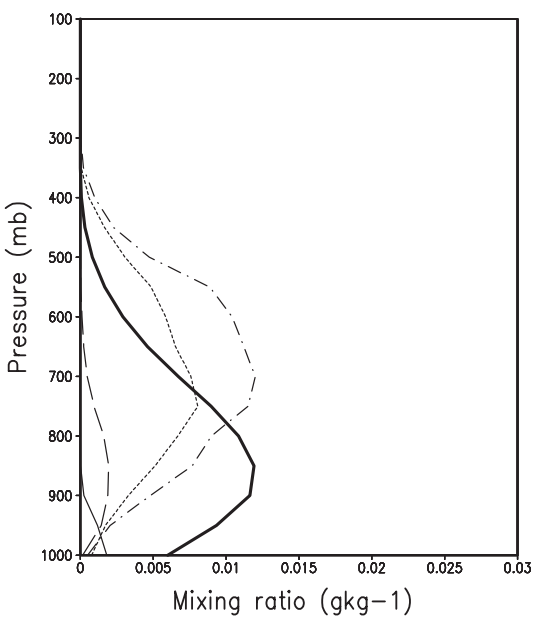

(d)

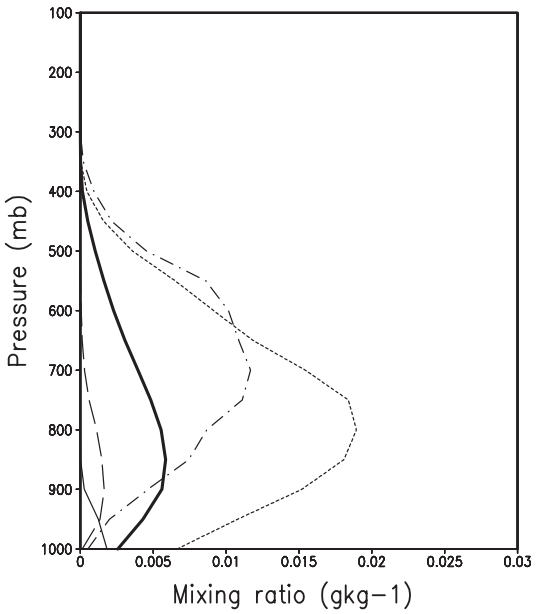

Fig. 7. Vertical distribution of water species, obtained from (a) Exp1 and (b) Exp4, averaged over the heavy rainfall region (32.3-41.2N, 121.5-131.3E) during the 24-h hrs, the results from the heavy snowfall simulation during the 36-h hrs, (c) Exp1 and (d) Exp4, averaged over the heavy snowfall region (34.0-36.5N, 125.2-128.4E). Results are obtained with the 5-km grid interval experiments. 
(a)

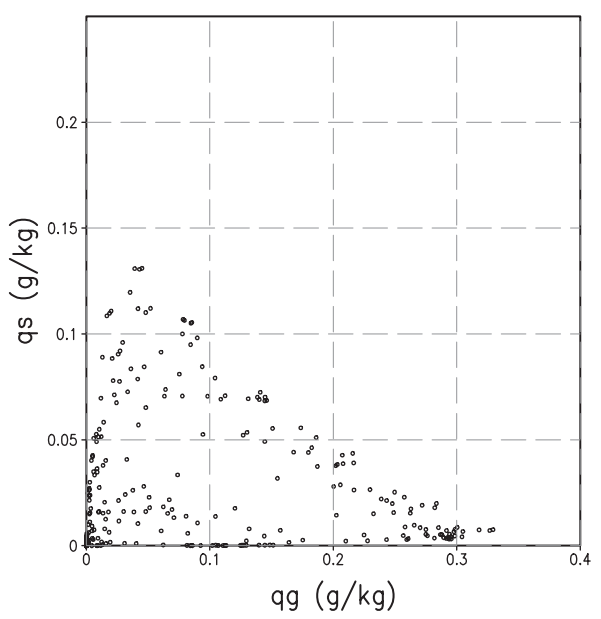

(b)

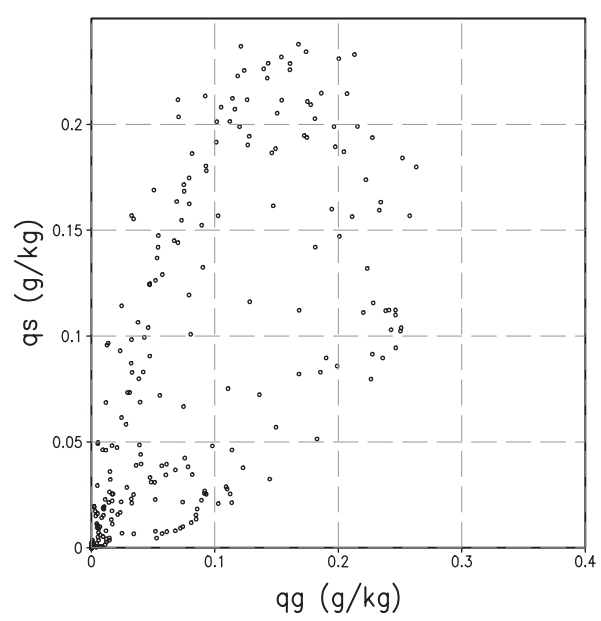

(c)

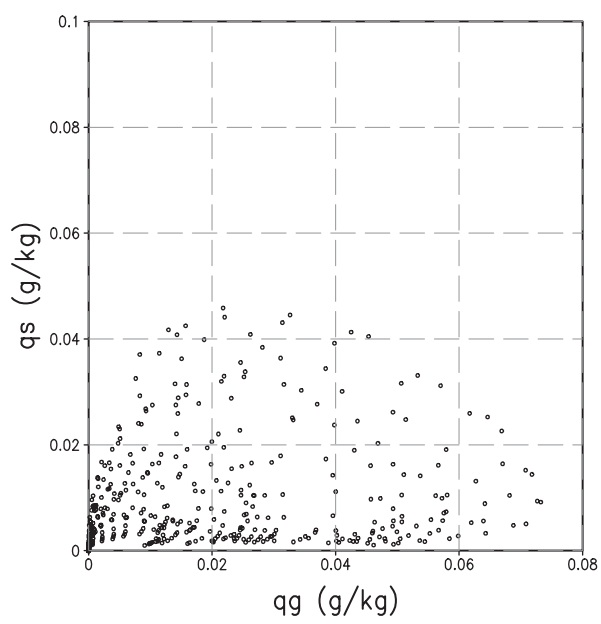

(d)

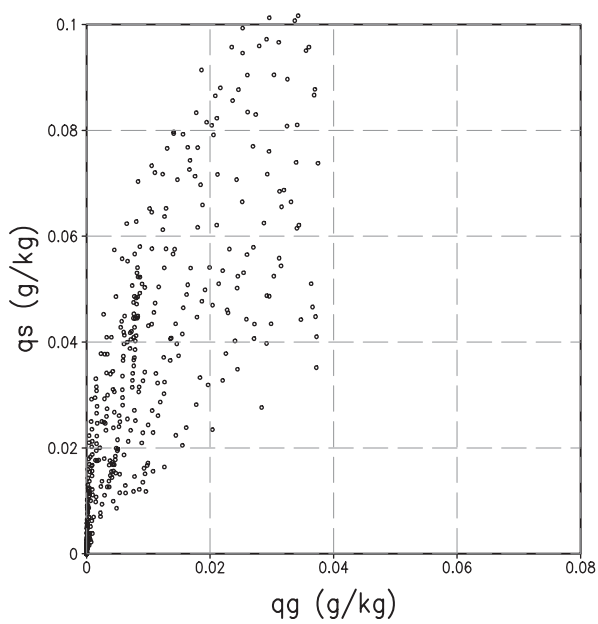

Fig. 8. Scatter plots of $q_{g}$ versus $q_{s}$ averaged over the heavy rainfall region (123-129E, 35-38N) during the 24-hr simulation period, obtained from (a) Exp1 and (b) Exp4, and the corresponding results obtained for the snowfall experiments, (c) Exp1 and (d) Exp4, over the heavy snowfall region (125-131E, $35-39.5 \mathrm{~N}$ ) during the $36-\mathrm{hr}$ simulation period. The plotted points in the figures are the values in overlapping layer of $q_{g}$ and $q_{s}$ from $600 \mathrm{hPa}$ to $100 \mathrm{hPa}$ for the heavy rainfall, and from $1000 \mathrm{hPa}$ to $400 \mathrm{hPa}$ for the heavy snowfall case. Results are obtained with the 5-km grid interval experiments.

\section{Concluding remarks}

A new method has been introduced of handling partially rimed species within the framework of an existing simple single-moment bulk microphysical scheme. This scheme is designed to alleviate the effects of the separation of precipitating ice particles into distinct rimed graupel and unrimed snow categories with clearly defined properties and fallspeeds. The method used is to merge the categories by mass-weighting the fallspeeds and modifying accretion rates consistently, which has the effect of treating all the particles in an intermediate way with a dependence on their degree of riming.

The effects of this scheme are dominated by the elimination of snow accretion by graupel that reduces graupel and increases snow thereby leading to more atmospheric hydrometeor mass and reduced surface precipitation rates as the cloud ma- 
tures. It could be argued that the rate of production of graupel by this accretion process was previously dependent on the clear fallspeed separation, and so was to some extent spurious given the common histories of the particles as they rime which would reduce relative fallspeeds and self-accretion among them. A secondary effect of the change is to permit partially rimed particles to remain at higher levels in convective clouds due to the reduced fallspeeds.

Tests of the new method have shown some promising results. The experiments have shown a potential to reduce a previous precipitation high bias in WSM6 due to the reduced production of graupel. Furthermore the surface precipitation type in a winter snowstorm case was more realistically simulated with the new scheme. A systematic underestimation of snow and overestimation of graupel in the WSM6 that was indicated by the previous studies (e.g., Lin et al. 2006; Tao et al. 2007) is expected to be alleviated by the introduction of the new falling velocity. Modifications to the hydrometeor distribution in the atmosphere could also be important for comparisons with remote sensing data and for cloud data assimilation.

While this scheme is well suited to simulations of individual clouds, and cloud systems such as squall lines where new clouds form separately from older ones, the scheme has a limitation in situations where new clouds may grow among older clouds, because in those cases graupel from a new cloud may indeed coexist with snow from an older cloud while the scheme will tend to merge them, possibly precipitating the snow out more quickly, and the graupel more slowly, than it should. It would not be possible to both remedy this situation and have the new proposed partially rimed treatment in a bulk microphysical scheme with only snow and graupel as species. These processes could both be addressed more accurately with multiple intermediate bins representing degrees of riming, but this would add significant computational cost associated with more species, so in this paper we focus on the new partial riming treatment, because the assumption of clouds growing separately is reasonable in the majority of cases.

The new method introduced here was implemented in WRF version 3.0 which was released in April 2008.

\section{Acknowledgements}

This study was supported by the Korean Foundation for International Cooperation of Science\&
Technology (KICOS) through a grant provided by the Korean Ministry of Science \& Technology (MOST) in 2007, and the Climate Environment System Research Center sponsored by the KOSEF.

\section{References}

Chen, F. and J. Dudhia, 2001: Coupling an advanced land surface-hydrology model with the Penn State-NCAR MM5 modeling system. Part I: Model implementation and sensitivity. Mon. Wea. Rev., 129, 569-585.

Dudhia, J., 1989: Numerical study of convection observed during the winter monsoon experiment using a mesoscale two-dimensional model. $J$. Atmos. Sci., 46, 3077-3107.

Hong, S.-Y. and J.-O.J. Lim, 2006: The WRF SingleMoment 6-Class Microphysics Scheme (WSM6). J. Korean Meteor. Soc., 42, 129-151.

Hong, S.-Y., Y. Noh, and J. Dudhia, 2006: A new vertical diffusion package with an explicit treatment of entrainment processes. Mon. Wea. Rev., 134, 2318-2341.

Hong, S.-Y., J. Dudhia, and S.-H. Chen, 2004: A revised approach to ice-microphysical processes for the bulk parameterization of cloud and precipitation. Mon. Wea. Rev., 132, 103-120.

Jung, B.-J., S.-Y. Hong, M.-S. Suh, and D.-K. Rha, 2005: A Numerical study of dynamical and thermodynamical characteristics associated with a heavy snowfall event over the Korean peninsula on 4-5 March 2004. J. Korean Meteor. Soc., 41, 387-399.

Kain, J. and M. Fritsch, 1993: Convective parameterization for mesoscale models : The Kain- Fritsch scheme. The representation of cumulus convection in numerical models, Meteor. Monogr., 24, Amer. Meteor. Soc., 165-170.

Lin, Y., B.A. Colle, C. Woods, and B.F. Smull, 2006: Verification of WRF for the 4-5 December 2001 IMPROVE-2 Event over the Central Oregon Cascades. The $7^{\text {th }}$ WRF workshop, 19-22 June, Boulder, Colorado. (Proceeding is available at http://wrf-model.org).

Lin, Y.-L., R.D. Farley, and H.D. Orville, 1983: Bulk parameterization of the snow field in a cloud model. J. Appl. Meteor., 22, 1065-1092.

Mlawer, E.J., S.J. Taubman, P.D. Brown, M.J. Iacono, and S.A. Clough, 1997: Radiative transfer for inhomogeneous atmosphere: RRTM, a validated correlated-k model for the long wave. J. Geophys. Res., 102(D14), 16663-16682.

Reisner, J., R.M. Rasmussen, and R.T. Bruintjes, 1998: Explicit forecasting of supercooled liquid water in winter storms using the MM5 mesoscale model. Quart. J. Roy. Meteor. Soc., 124, 10711107.

Skamarock, W.C., J.B. Klemp, J. Dudhia, D.O. Gill, 
D.M. Barker, W. Wang, and J.G. Powers, 2005: A Description of the Advanced Research WRF Version 2. NCAR technical note, NCAR/TN468+STR. (Available at http://www.mmm.ucar. edu/wrf/users/docs/arw_v2.pdf)

Tao, W.-K., J.J. Shi, S.S. Chen, S. Lang, S.-Y. Hong, G. Thompson, C. Peters-Lidard, A. Hou, S. Braun, and J. Simpson, 2007: New, improved Goddard bulk-microphysical schemes for studying precipitation processes in WRF. Part I: Comparisons with other schemes. Mon. Wea. Rev., (Submit- ted).

Thompson, G., P.R. Field, W.D. Hall, and R.M. Rasmussen, 2006: A new bulk microphysical parameterization for WRF and MM6. The $7^{\text {th }}$ WRF workshop, 19-22 June, Boulder, Colorado. (Proceeding is available at http://wrf-model.org).

Thompson, G., R.M. Rasmussen, and K. Manning, 2004: Explicit forecasts of winter precipitation using an improved bulk micro-physics scheme. Part I: Description and sensitivity analysis. Mon. Wea. Rev., 132, 519-542. 